\title{
Mechanical loading of adipose derived stromal cells causes cell alignment $^{*}$
}

\author{
David A. Gonzales, Alice S. Ferng, Chris P. Geffre, Jamie L. Borg, Michael Miller, John A. Szivek
}

Orthopaedic Research Laboratory, University of Arizona, Tucson, USA.

Email: davidg1@email.arizona.edu

Received 22 February 2011; revised 7 April 2011; accepted 16 April 2011.

\begin{abstract}
Osteoarthritis is a debilitating disease that affects hundreds of millions of people worldwide. Current research involving growth and characterization of adipose derived stromal cells (ADSC) in vitro offers a potential solution for the treatment of cartilage defects that will allow patients to return to the physical activities they were involved in. Studies have shown that fibroblast cells grown in vitro respond to cyclic mechanical stretching by orienting in a direction perpendicular to the direction of stretch. ADSCs were isolated from human peripatellar adipose tissue discards. Cells were cultured until confluent and seeded at a density of approximately 105 cells in silicone wells pretreated with ProNectin-F Plus. After stretching, relative alignment of the cells was ascertained using imaging software. Stretching cells for $3,4,8$ and 12 hours resulted in noticeable cellular alignment of approximately $60^{\circ}$ relative to the direction of loading. Cell alignment is crucial for developing tissueengineered cartilage that has similar mechanical properties to native cartilage. Mechanically loading cells is one method to achieve cell alignment. Since cell differentiation will be initiated after alignment, the resulting chondrocytes will be aligned, leading to organized collagen formation and resulting in a hyaline-like cartilage structure.
\end{abstract}

Keywords: Adipose Derived Stromal Cells; Mechanical Loading; Chondrogenesis; Osteoarthritis

\section{INTRODUCTION}

Cartilage defects inevitably lead to osteoarthritis which is a debilitating disease that affects hundreds of millions of people worldwide [1]. Current treatments for focal cartilage defects have had limited success rates and include focal drilling or defect perforation (marrow stimu-

*We would like to thank Howard Hughes Medical Institute; Grant \# 52003749 for supporting this research. lation), osteochondral auto- or allo-graft transplantation (mosaicplasty), and autologous chondrocyte implantation (ACI) [2-12]. The standard of care for treatment of advanced osteoarthritis is total joint replacement. Recent studies have concluded that adipose tissue is a significant source of multipotent cells which can be differentiated into cartilage cells [13,14]. Extension of focal defect repair strategies using adult stem cells instead of chondrocytes shows promise in the treatment of small and large cartilage defects and the potential for developing resurfacing strategies for patients with extensive damage due to early stages of osteoarthritis. Success in a preliminary study that used adipose derived stromal cells placed into the joints of an animal model $[15,16]$ suggested that this cell population was ideally suited for use in a technique that could be developed to regenerate hyaline articular cartilage in large cartilage defects. A successful strategy for regeneration of hyaline articular cartilage requires a technique which facilitates the formation of cartilage tissue with cells and collagen that are stratified through the section of the cartilage and oriented in the directions observed in native articular cartilage. Techniques reported in the literature to align cartilage cells causing them to form aligned tissue include substrate patterning $[17,18]$ and loading to induce alignment [19-21]. Successful alignment of fibroblasts documented by Neidlinger-Wilke et al lead to this study. The goal of this study was to determine whether adult stromal cells extracted from adipose tissue could be aligned by cyclically loading the cells to a specific strain at a specific frequency and a given time duration. A secondary goal was to determine how long this cell population remained aligned following loading.

\section{MATERIALS AND METHODS}

\subsection{Silicon Dish Preparation}

Silicone dishes were formed in custom designed metal molds (Figure 1(a)) using Sylgard 184 Silicone Elastomer Base and Sylgard 184 Silicone Curing Agent in a 


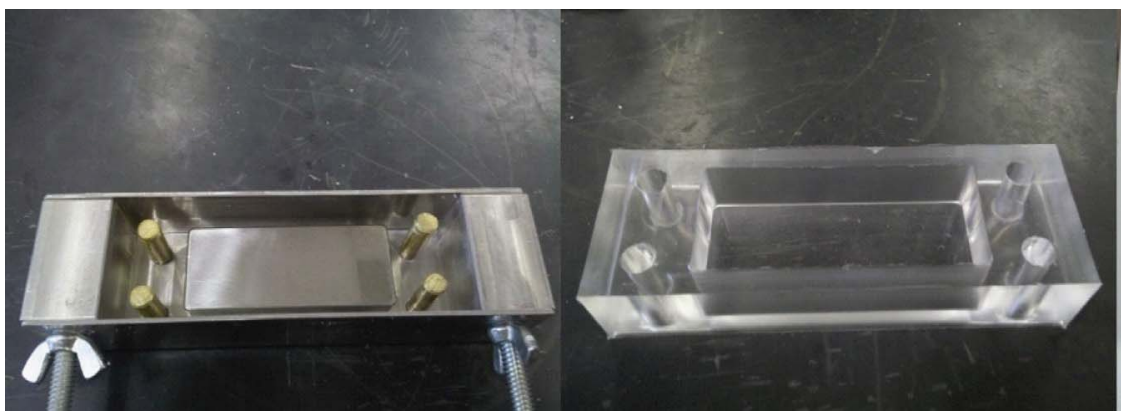

(a)

(b)

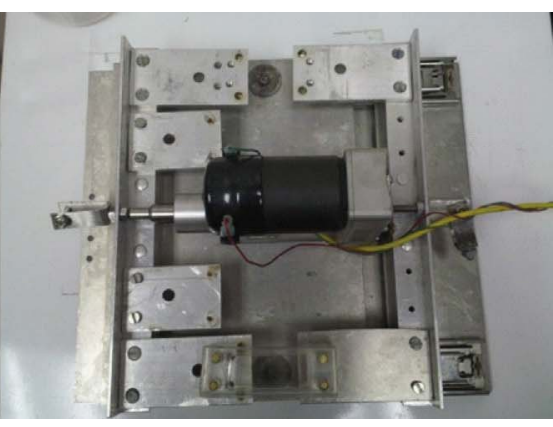

(c)

Figure 1. The metal mold (a) to form the silicone dishes (b). The cell stretching machine (c).

10 : 1 ratio as per the manufacturer's procedure (Dow Corning, Midland, MI). The surfaces of the molds were polished to a 1200 grit finish. The silicone dishes (Figure 1(b)) had a smooth rectangular surface area of 15 $\mathrm{cm}^{2}$. The molds were allowed to set for a minimum of 8 hours and then cured for 4 hours at $90^{\circ} \mathrm{C}$. Prior to seeding dishes with cells, the silicone dishes were steam sterilized in an autoclave and then treated with a 0.01 $\mathrm{mg} / \mathrm{mL}$ solution of ProNectin-F Plus for $5 \mathrm{~min}$ (Sigma-Aldrich, St. Louis, MO). They were also rinsed with dication-free phosphate buffered saline (DCF-PBS) (Sigma-Aldrich) twice before seeding.

\subsection{ADSC Isolation and Culture}

Adipose derived stromal cells (ADSC) were obtained from human peripatellar adipose tissue. The tissues were obtained from patients according to an IRB approved protocol. Multiple samples were used from female patients, with ages ranging from 47 to 75 years of age.

The ADSCs were digested using the technique previously described by Szivek et al. [22]. The tissue samples were cut into small 1 - $2 \mathrm{~cm}$ cubes and digested in a 50\% ratio with digestion media in a $37^{\circ} \mathrm{C}$ shaker bath for 1 hour. Digestion media consisted of $4500 \mathrm{U} / \mathrm{mL}$ collagenase I (EMD Biosciences, San Diego, CA) and 8 $\mathrm{mg} / \mathrm{mL}$ Bovine Serum Albumen (Sigma-Aldrich) dissolved in dication-free phosphate buffered saline (DCF-PBS) (Sigma-Aldrich). ADSCs were isolated from the digested fluid by fractional centrifugation for $4 \mathrm{~min}$ at $700 \mathrm{~g}$. The resulting cell pellet was suspended in Dulbecco's Modified Eagle Medium (DMEM) (Sigma-Aldrich) supplemented with $10 \%$ fetal bovine serum (FBS) (Sigma-Aldrich) 1\% penicillin-streptomycin (SigmaAldrich), $0.25 \mathrm{ng} / \mathrm{mL}$ Transforming Growth Factor- $\beta 1$ (TGF- $\beta 1$ ), $5 \mathrm{ng} / \mathrm{mL}$ Epidermal Growth Factor (EGF), and $1 \mathrm{ng} / \mathrm{mL}$ bovine Fibroblast Growth Factor (bFGF) and seeded into a T-150 cell culture flask. Cells were maintained in an incubator at $37^{\circ} \mathrm{C}$ and $5 \% \mathrm{CO}_{2}$. The cells were allowed to reach confluence, and passages 3-4 were used in these experiments.

\subsection{Dynamic Cell Loading}

ADSCs were seeded onto the ProNectin treated silicone wells at a minimum density of approximately 6667 cells $/ \mathrm{cm}^{2}$ (approximately $10^{5}$ cells total per well) as well as 13333 cells $/ \mathrm{cm}^{2}$ (approximately $2 * 10^{5}$ cells total per well) and allowed to attach for a 24 hour period. Cells were photographed prior to stretching. Three separate locations were imaged near the central portion of the dish. Previous studies utilizing silicone dishes with a similar design for uniaxial loading demonstrated that the loading region experiences nearly uniform stress [23]. Dishes were cyclically loaded at $1.0 \mathrm{~Hz}$ and $10 \%$ strain for $0,2,3,4,8$ and 12 h using a custom designed cyclic loading machine (Figure 1(c)) housed within the incubator. At each time period, the dishes were removed and photographed at the same three locations. In addition, an unstretched set of cells was also photographed for comparative analysis [24]. The cells were fixed in $10 \%$ methanol for 5 min and stained using haematoxylin and eosin.

\subsection{Analysis of Cell Orientation}

Images of stretched and control cells were analyzed (Figure 2) and the relative cell angles were measured with respect to the horizontal axis using imaging software. The horizontal (stretch direction) was defined to be $0^{\circ}$. For each image, cells with a measureable orientation were evaluated. The average of the total measured angles for each time point was taken, as well as the standard deviation between the various samples. A paired t-test was conducted comparing the initial control values with the stretched values for each time point. Images of stretched cells were also analyzed at 1, 2 and 3 hours post-stretch and the average angles were measured and analyzed using the same methods described above.

\section{RESULTS}

The silicone dishes showed no visible signs of damage after the loading period, and the cyclic loading machine 


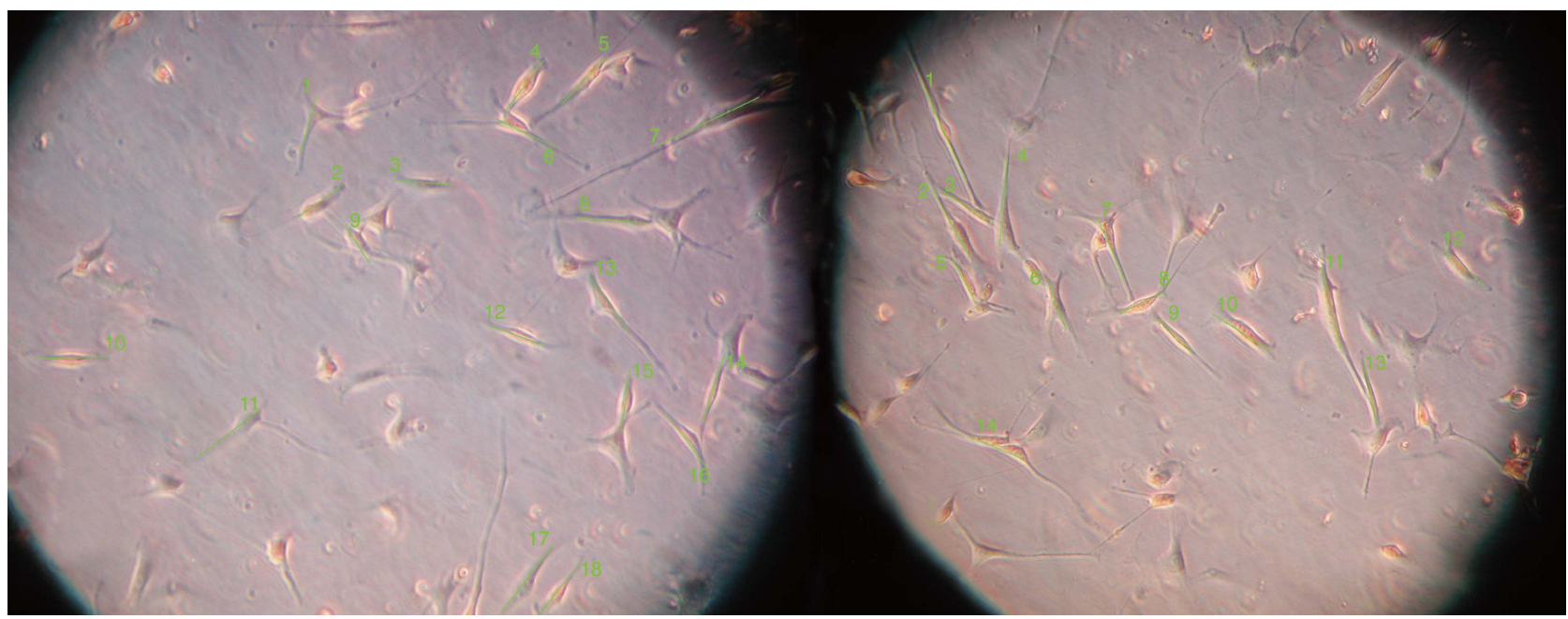

(a)

(b)

Figure 2. Randomly oriented cells (a) compared with cells beginning to show alignment after eight hours of loading (b).

maintained stretch frequency and stretch length accurately during the entire loading period. For a loading period of 2 hours there was no significant difference between stretched and non-stretched cells $(p=0.4)$.

There was also no significant difference in orientation between cells seeded at 6667 cells/ $\mathrm{cm}^{2}$ and cells seeded at 13333 cells $/ \mathrm{cm}^{2}$ after stretching cells for a period of 3 hours $(p=0.4)$. ADSC orientation perpendicular to stretching direction was apparent in stretched cells after periods of 3 and 4 hours, and a relatively random orientation was noted in non-stretched cells. For a stretching period of 3 hours, the average angle relative to the axis of loading was $57.8^{\circ} \pm 5.1$, compared to an average control angle of $45.7^{\circ} \pm 4.0(p<0.001)$. For cells stretched for 4 hours, the average measured angle was $60.1^{\circ} \pm 1.6$, with an average control angle of $43.3^{\circ} \pm 3.3(p=0.004)$. Cells stretched for an 8 hour period had an average angle of $62.5^{\circ} \pm 3.6$, with an average control angle of $41.8^{\circ} \pm$ $2.6(p=0.002)$. Cells stretched for 12 hours had an average angle of $59.9^{\circ} \pm 3.0$, with an average control angle of $45.7^{\circ} \pm 2.6(p=0.002)$ (Figure 3$)$.

After a 3-hour stretching period, cells were relieved of tension and imaged every hour for several hours. After 1-hour post stretch, cells maintained their alignment compared to the values recorded immediately after stretching ( $p=0.04)$. However, after two hours, random cell orientation was apparent as seen in Table 1 ( $p=$ 0.17).

\section{DISCUSSION}

This study was conducted to determine whether the alignment of ADSCs could be changed when subjected to cyclic mechanical stretching. Our results indicate that ADSCs do respond to stretching stimuli, and that this

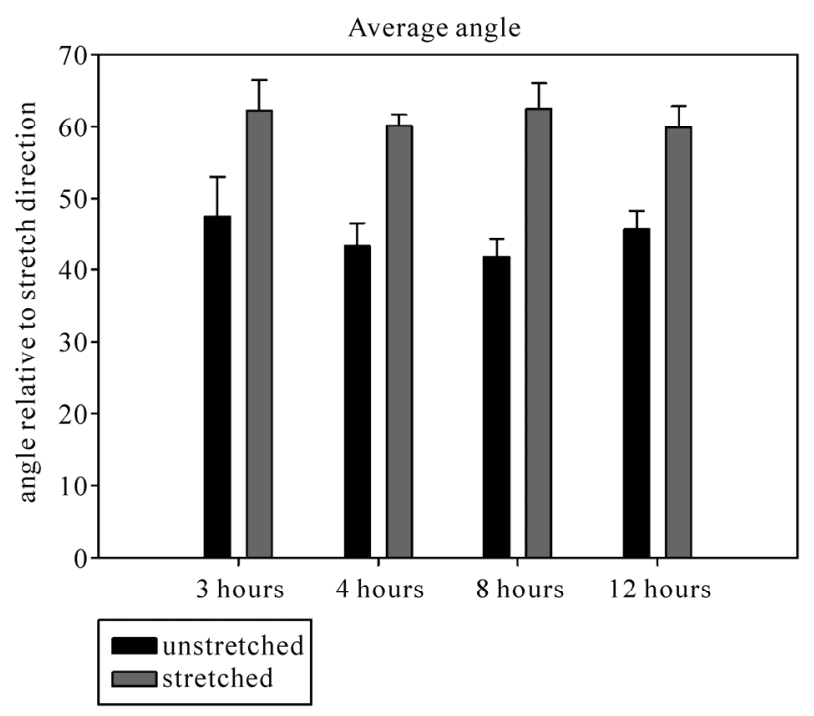

Figure 3. Graphical representation of the average measured angles between various time points.

Table 1. T-test analysis of cell orientation after a 3 hours stretching period.

\begin{tabular}{rcccc}
\hline & init & $3 \mathrm{hr}$ & $3+1 \mathrm{hr}$ & $3+2 \mathrm{hr}$ \\
\hline well \#1 & 45.7 & 55.9 & 51.6 & 47.8 \\
well \#2 & 46.8 & 57.1 & 49.7 & 56.4 \\
well \#3 & 46.8 & 54.7 & 56.3 & 45.7 \\
well \#4 & 42 & 57.7 & 55.1 & 54.9 \\
average & 45.2 & 56.3 & 53.6 & 50.8 \\
t-test & & 0.006883 & 0.03802 & 0.16763 \\
\hline
\end{tabular}

strategy could be used to prime cells prior to use in cartilage tissue engineering. In these experiments, complete 
perpendicular alignment was not achieved. To achieve nearly perpendicular cellular alignment in relation to stretching direction, additional strategies will be assessed, including combinations of faster load rates and/or longer loading times as well as different cellular densities. Our results agree with studies by NeidlingerWilke [24] on fibroblasts that demonstrated fibroblast alignment within three hours. Their work with fibroblasts did demonstrate continued alignment for up to several hours immediately after the stretch period, however based upon our preliminary studies, ADSCs appear to demonstrate a degenerative alignment after a 2-hour period. Further studies will attempt to determine the mechanism behind this change and whether induction of chondrogenesis by the addition of growth factors will halt the degenerative alignment.

Cell alignment is crucial for developing tissue-engineered cartilage that has the same structure as hyaline articular cartilage. This structure is believed to be the reason native hyaline cartilage is resilient and has appropriate mechanical properties for long term load bearing [25]. Mechanically stretching cells is one approach which will induce cell alignment. Growing tissue engineered cartilage may provide an alternative to total joint replacement as a treatment for widespread cartilage damage noted in OA patients [26,27], but this will only be possible if resilient hyaline cartilage can be grown for the joints of patients. Adipose derived cells collected from the tissues of patients can be readily accessed and expanded. Differentiation occurs once cells are placed into a chondrogenic environment and it is expected that cell alignment will be retained for some period following alignment. This will ensure hyaline cartilage formation with the appropriate tissue structure.

\section{REFERENCES}

[1] Buckwalter, J.A. and Mankin, H.J. (1997) Articular cartilage. II. Degeneration and osteoarthritis, repair, regeneration, and transplantation. Journal of Bone and Joint Surgery, 79, pp. 612-632.

[2] Williams, R.J. 3rd and Harnly, H.W. (2007) Microfracture: Indications, technique and results. Instructional Course Lectures, 56, 419-428.

[3] Peterson, L., Brittberg, M., Kiviranta, I., Akerlund, E.L. and Lindahl, A. (2002) Autologous chondrocyte transplantation: Biomechanics and long-term durability. American Journal of Sports Medicine, 30, 2-12.

[4] Marcacci, M., Kon, E., Zaffagnini, S., Iacono, F., Neri, M.P., Vascellari, A., Visani, A. and Russo, A. (2005) Multiple osteochondral arthroscopic grafting (mosaicplasty) for cartilage defects of the knee: Prospective study results at 2-year follow-up. Arthroscopy, 21, 462-470. doi:10.1016/j.arthro.2004.12.003

[5] Ocelus, S.M. (2000) Autologous cultured chondroctes for the treatment of knee cartilage injury. Orthopaedic
Nursing, 19, 19-27.

doi:10.1097/00006416-200019040-00006

[6] Huntley, J.S., Bush, P.G., McBirnie, J.M., Simpson, A.H. and Hall, A.C. (2005) Chondrocyte death associated with human femoral osteochondral harvest as performed for mosaicplasty. Journal of Bone and Joint Surgery, 87, 351-360. doi:10.2106/JBJS.D.02086

[7] Brittberg, M., Tallheden, T., Sjorgren-Jansson, B., Lindahl, A. and Peterson, L. (2001) Autologous chondroctes used for articular cartilage repair: An update. Clinical Orthopaedics and Related Research, 391 Suppl, S337S3348. doi:10.1097/00003086-200110001-00031

[8] Knutsen, G., Drogset, J.O., Engebretsen, L., Grontvedt, T., Isaksen, V., Ludvigsen, T.C., Roberts, S., Solheim, E., Strand, T. and Johansen, O. (2007) A randomized trial comparing autologous chondrocyte implantation with microfracture. Findings at five years. Journal of Bone and Joint Surgery, 89, 2105-2112. doi:10.2106/JBJS.G.00003

[9] Almqvist, K.F., Dhollander, A.A.M., Verdonk, P.C.M., Forsyth, R. and Verbruggen, G. (2009) Treatment of cartilage defects in the knee using alginate beads containing human mature allogenic chondrocytes. American Journal of Sports Medicine, 37, 1920-1929. doi:10.1177/0363546509335463

[10] Gikas, P.D., Bayliss, L., Bentley, G. and Briggs, T.W. (2009) An oberview of autologous chondrocyte implantation. Journal of Bone and Joint Surgery, 91, 997-1006. doi:10.1302/0301-620X.91B8.21824

[11] Frisbie, D.D., Lu, Y., Kawcak, C.E., DiCarlo, E.F., Binette, F. and McIlwraith, C.W. (2009) In vivo evaluation of autologous cartilage fragment-loaded scaffolds implanted into equine articular defects and compared with autologous chondrocyte implantation. American Journal of Sports Medicine, 37, Supplement 1, 71S-80S. doi:10.1177/0363546509348478

[12] Getgood, A., Brooks, R., Fortier, L. and Rushton, N. (2009) Articular cartilage tissue engineering: Today's research, tomorrow's practice? Journal of Bone and Joint Surgery $(B r)$, 91, 565-576. doi:10.1302/0301-620X.91B5.21832

[13] Guilak, F., Estes, B.T., Diekman, B.O., Moutos, F.T. and Gimble, J.M. (2010) Nicolas Andry award: Multipotent adult stem cells from adipose tissue for musculoskeletal tissue engineering. Clinical Orthopaedics and Related Research, 468, 2530-2540. doi:10.1007/s11999-010-1410-9

[14] English, A., Jones, E.A., Corscadden, D., Henshaw, K., Chapman, T., Emery, P. and McGonagle, D. (2007) A comparative assessment of cartilage and joint fat pad as a potential source of cells for autologous therapy development in knee osteoarthritis. Rheumatology, 46, 1676-1683. doi:10.1093/rheumatology/kem217

[15] Szivek, J.A., Wiley, D., Cox, L., Harris, D., DeYoung, D.W. and Grana, W.A. (2006) Stem cells can be extracted from adipose tissue and converted to chondrrocytes for tissue engineering. Scientific Session of the Academy of Surgical Research, Scottsdale, p. 5.

[16] Szivek, J.A., Wiley, D., Cox, L., Harris, D., Margolis, D.S. and Grana, W.A. (2007) Stem cells grown in dynamic culture on micro patterned surfaces can be used to engineer cartilage-like tissue. Orthopaedic Research So- 
ciety, San Diego, p. 434.

[17] Wang, J.H., Gia, F., Gilbert, T.W. and Woo, S.L. (2003) Cell orientation determines the alignment of cell-produced collagenous matrix. Journal of Biomechanics, 36, 97-102. doi:10.1016/S0021-9290(02)00233-6

[18] Wang, J.H., Yang, G., Li, Z. and Shen, W. (2004) Fibroblast responses to cyclic mechanical stretching depend on cell orientation to the stretching direction. Journal of Biomechanics, 37, 573-576. doi:10.1016/j.jbiomech.2003.09.011

[19] Wang, J.H., Goldschmidt-Clermont, P., Wille, J. and Yin, F.C. (2001) Specificity of endothelial cell reorientation in response to cyclic mechanical stretching. Journal of Biomechanics, 34, 1563-1572. doi:10.1016/S0021-9290(01)00150-6

[20] Dodd, J.G., Good, M.M., Nguyen, T.L., Grigg, A.I., Batia, L.M. and Standley, P.R. (2006) In vitro biophysical strain model for understanding mechanisms of osteopathic manipulative treatment. Journal of the American Osteopathic Association, 106, 157-166.

[21] Henshaw, D.R., Attia, E., Bhargava, M. and Hannafin, J.A. (2006) Canine ACL fibroblast integrin expression and cell alignment in response to cyclic tensile strain in three-dimensional collagen gels. Journal of Orthopaedic Research, 24, 481-490. doi:10.1002/jor.20050

[22] Szivek, J.A., Margolis, D.S., Schnepp, A.B., Grana, W.A. and Williams, S.K. (2007) Selective cell proliferation can be controlled with CPC particle coatings. Journal of Biomedical Materials Research A, 81A, 939-947. doi:10.1002/jbm.a.31116

[23] Pfister, B.J., Weihs, T.P., Betenbaugh, M. and Bao, G. (2003) An in vitro uniaxial stretch model for axonal injury. Annals of Biomedical Engineering, 31, 589-598. doi:10.1114/1.1566445

[24] Neidlinger-Wilke, C., Grood, E., Claes, L. and Brand, R. (2002) Fibroblast orientation to stretch begins within three hours. Journal of Orthopaedic Research, 20, 953956. doi:10.1016/S0736-0266(02)00024-4

[25] Hunziker, E.B., Quinn, T.M. and Hauselmann, H.J. (2002) Quantitative structural organization of normal adult human articular cartilage. Osteoarthritis Cartilage, 10, 564572. doi:10.1053/joca.2002.0814

[26] Grande, D.A., Breitbart, A.S., Mason, J., Paulino, C., Laser, J. and Schwartz, R.E. (1999) Cartilage tissue engineering: Current limitations and solutions. Clinical Orthopaedics and Related Research, 367, Supplement 1, S176-S185. doi:10.1097/00003086-199910001-00019

[27] Solchaga, L.A., Goldberg, V.M. and Caplan, A.I. (2001) Cartilage regeneration using principles of tissue engineering. Clinical Orthopaedics and Related Research, 391, Supplement 1, S161-S170. doi:10.1097/00003086-200110001-00016 